Sixth World Conference on Injury Prevention and Control

\title{
Introduction
}

\section{B Pless}

\section{Presentations from the Sixth World Conference on Injury Prevention and Control}

$\mathrm{T}$

he Sixth World Conference on Injury Prevention and Control, held in

Montreal in May 2002, is now just a smattering of lingering memories. For some, the most enduring of these may be the uncharacteristically cold and wet weather. For most, however, I hope that mingled with the downers are many high notes, including many memorable presentations.

I am not foolish, courageous or wise enough to single out any individual papers. But as a member of the organising committee I was able to suggest names of those who I thought would deliver-and deliver well-useful State of the Art or Plenary papers. Unfortunately, although we struggled with the question in both languages, we were not able to draw a clear line between the two. And, in any case, the distinction may be unimportant. What is important is that subscribers to Injury Prevention are receiving this supplement, which includes all the State of the Art papers, thanks to the generosity of the sponsors (National Institute for Occupational Safety and Health, Centers for Disease Control and Prevention and the National Center for Injury Prevention and Control, Centers for Disease Control and Prevention, Department of Health and Human Services). We are extremely grateful for this on behalf of the entire injury prevention community. Readers of another journal will receive the Plenary papers.

We are proud to have this opportunity to offer this memory jogger for those who may have been inattentive during these presentations (or who overslept, for which I credit the marvellous restaurants and night life that Montreal offers), and a set of important pieces for those unable to attend.

To my mind, a State of the Art presentation should provide a comprehensive and authoritative overview of the latest developments on a particular topic or issue at the moment of delivery. Most of the papers in this supplement do just that; some, however, take another tack. The latter present the most recent work of the author(s), no doubt on the assumption that as leaders in the field, this in effect represents the cutting edge.

Regardless of which type of paper is being considered, there is an implicit assumption that I am not certain is always true. I make this point as an editor and do not intend it to apply in any particular way to the papers in this supplement. In fact, if I am in the least correct, the concern I am about to express applies far more to the original articles we and most other journals publish. That concern is that too little of what finds its way into print is as cumulative as it should be. If it were, the most recent paper on any subject could be viewed as a mini State of the Art publication.

I try to teach my students that the introduction to a scientific paper should build a case for what follows in the remainder of the paper. That case rests on knowing what has been done in the field, why the evidence to date is insufficient, and how the paper you are writing proposes to remedy these insufficiencies. If all this were done, done well, and succinctly, that one or two page introduction would be a State of the Art in miniature. Having 40 or 50 minutes to elaborate on such points, as did the presenters in this issue, permits a much more comprehensive elucidation of these key elements.

In my view, some authors succeed in setting the scene remarkably well; others perhaps less so. The same applies to the papers in this supplement. All provide much food for thought and memorable contributions to a field that is not only growing in depth but in breadth as well. Certainly it never occurred to me that included in this supplement would be papers on domestic violence, urban safety, etc. My field of vision was embarrassingly restricted and reading these has expanded my horizons greatly. I trust it will do the same for yours.

\section{Author's affiliation}

I B Pless, Editor

I B Pless; barry.pless@mcgill.ca 